One may say without doubt, that without any truss treatment whatever, the thickness of the hernial sac varies to a remarkable degree. It presents a varying degree of thickness from that of the tunica vaginalis testis to that of the perietal peritoneum lining the abdominal wall.

A microscopical examination of these two structures shows that their minute anatomy is identical. They pnesent a thin endothelial lining, the substanee of the sac wall being formed of a more or less condensed layer of connective tissue.

I have examined over 100 sacs removed at operation. The varying degree of thickness depends on the development of this connective tissue or fibrous layer. The thickmess of the sac does: not depend on its size or extent. It is not common to find a sac presenting equal thickness with the tunica vaginalis testis, it being easy to compare them as one dissects the one off the other.

The tunica vaginalis testis shows up as a white thick non-translucent covering to the testicle, especially in young subjects. I have seen a small pyriform sac on more than one occasion identical in thickness and appearance with the tunica vaginalis testis, and a large sac, such as is seen in caecal herniae, may be also of considerable thickness. The development of the connective tissue of the sac wall does not apparently depend on the size of the sac, though as a rule thin sacs are large sacs.

Can we make any deductions from the histological charactors of the sac as to its probable congenital or acquired origin? One would expect that the acquired sac would resemble more nearly the parietal peritoneum, and the congenital sac more closely the tunica vaginalis testis.

A small thick sac is often associated with a narrow inguinal canal and a small external abdominal ring, so much so that apart from removing the sac, it is unnecessary to attempt to narrow the canal or the ring. In thesecases the bowel rarely descends into the sac, and there seems very little doubt that it is part of the funicular process and congenital in origin.

It seems probable that the varying degrees of thickness of the hernial sac represent stages in its natural obliterative process. Microscopic examination does not seem to me to afford any aid in distinguishing the acquired from the congenital hernial sac, although $I$ am inclined to view the small thick sac as always congenital in origin. It is only natural to suppose that a small acquired sac will resemble more nearly the parietal peritoneum than the tunica vaginalis testis.

If the funicalar process which has almost become ob. literated be examined, it will be found that the endothelial lining disappears before its increasing fibrous wall.

Conclusions.

As a result of these observations, it is perhaps justifiable to suggest the following conclusions.

1. That in early childhood clinical evidence, by examin ing the spermatic cords of apparently normal children, shows that between 50 and 75 per cent.present thickening due to incomplete closure of the funicular process.

2. That the anatomical conditions present in operated cases support the view of a congenital origin, as shown by the relation of the sac to its coverings, and its presence in spite of a narrow canal and a small external abdominal ring.

3. That the histological and naked-eye appearances of the sac in most cases do not afford reliable evidence of its congenital origin or otherwise, although a markedly thickened sac, if small, is suggestive of the embryonic condition.

\section{THE TREATMENT OF}

\section{CHRONIC EMPYEMA BY HYPERAEMIA AND HYPERTRANSUDATION.}

By J. STAVELEY DICK, M.B., B.Сн.R.U.I.

Mr. R. J. Godres in his classical lectures ${ }^{1}$ on Empyema, delivered more than twenty years ago, said that

A very grave prognosis must always be given in cases of empyema which will not heal, and the question arises as to what, if anything, can be done for their relief.

Most people with practical experience will agree with Mr. Godlee's reply to his own question, that adequate drainage - adequate, that is to say, not merely in regard to the size of the opening but also in regard to its position and the length of time it is maintained -is the finst condition. of cure.

It happens, however, now and again, that though efficient drainage has been secured and maintained, a cavity remains which Nature's unaided efforts fail to obliterate. Can anything of value besides drainage, short of Estlander's, Schede's, or similar radical operation, be done in such circumstances? Mr. Godlee tried spongegrafting, ${ }^{2}$ but the results were not encouraging.

Sir James Barr has suggested the use of an appropriate vaccine,,$^{3}$ but he does not offer any positive evidence of its suitability or necessity; and there seem to be certain con. siderations which militate against the general adoption of this suggestion in this particular type of case. In really old-standing empyemata we know that the walls of the cavity consist of dense fibrous tissue of considerable thickness and poorly supplied with blood. Hitherto it has not been proved that in such cases the continuation of the infective process is due to a deficiency of antibacterial substances in the blood; and when we reflect that spontaneous auto-inoculations have probably been in progress for months, or at all events whether this be so or not, that the patient's general health has greatly improved as a result of drainage, tonics and fresh air, it appears not unlikely that the persistence of the infective process is due rather to the limitation of the blood supply to the infected area than to an abnormally low opsonic index. Further, if "a mixed infection" be assumed to exist in chronic cavities of this kind, and the assumption. is mone than probable, then the technical difficulties incident to the preparation of an appropriate vaccine appear to be at present so considerable as seriously to depreciate the value of the suggestion, as a routine mode of treatment.

Apart altogether, however, from the doubt as to the actual necessity for a vaccine, and apart from the technical difficulties in the way of procuring an appropriate vaccine, is not the first and most rational step in this line of treatment rather to try the effect of such means as are available in order to increase the transudation of blood to the infected area? A vaccine may subsequently be required to supple. ment the effect, if a freer transudation of the blood with its existing opsonic content should fail to bring about a cure.

The following case of chronic empyema is submitted as evidence that measures to promote a freer transudation of blood to the infected area may in some cases of the kind be followod by the most gratifying results :

J.B., aged $8 \frac{1}{2}$ years, contracted pneumonia; six weeks later he "vomited" a large quantity of pus (?); cough and copious offensive expectoration followed.; six months later he was operated sive expectoration followed; six months later he was. operated portion of rib being resected in the mid-axillaxy line of the portion of rib being resected in the mid-axillary line of the right side. He then weighed three stones; he remained in hospital subsequently about four months, and then weighed almost four stones. He was sent to a convalescent homeat St. Anne's, wearing a drainage tube ; after a failure to reinsert the drainage tube, signs of reaccumulation of pus occurred. He first came under the writer's observation three weeks later he then had anorexia, headache, nausea, dyspnoea, and a temperature varying from subnormal in the morning to $102^{\circ}$ in the evening. A portion of rib was resected in the posterior axillary line, and about ten ounces of thick, jelly-like, slightly axillary line, and about ten ounces of thick, jelly-like, slightly offensive pus evacuated. This was followed for four months by satisfactory improvement, when failure to maintain adequate drainage was followed by recurrence of very acute symptoms of septic absorption. Four days after the return of fever, two inches of the next higher rib was resected in the line of the angle of the scapula, the corresponding periosteum and parietal pleura cut away, and the opening still further enlarged by dividing the structures between it and the second sinus. A surprisingly large quantity, about twenty ounces, of thin, odourless pus was evacuated. Two large drainage tubes were inserted; one was discontinued in six weeksand the other packed tightly with gauze, carried to the bottom of the cavity, and tubular drainage was maintained for nine months without difficulty. Six months 'after the final operation the capacity of the cavity was a little over two drachms; three months later it was practically the same. During these last three months it was practically the same. During these last three months it was possible to aspirate one-half to one drachm of pus each morning and antiseptic irrigations had been resorted to daily during this period.

The position, therefore, was that two years from the onset of pneumonia, and nine months from the final operation, there was still a cavity having a capacity of over two drachms, and secreting over one drachm pus daily; 
and it had, apparently, been in statu quo for three months, so that one began to despair of drainage alone effecting a complete cure.

It was under these circumstances that an attempt was made to effect a cure by increasing the transudation of blood to the infected area, suggested by perusal of a paper by Sir A. E. Wright, ${ }^{4}$ in which the pathology of different types of bacterial nidus is dealt with.

A cupping glass, with rubber exhaust, was employed; of suitable shape and of such a size as to include the sinus and portion of the chest wall bounding the cavity externally. Its application at first was rather painful. It is necessary, however, in such a case, to distinguish between the pain from pressure and the pain from suction, when the area" surrounding the sinus is more or less tender. While the cupping glass was in use the patient inflated a football (as he had previously been in the habit of doing for months), in the hope of securing a further local reexpansion, or, it may be, a localized emphysema of the portion of lung abutting on the cavity.

The cavity was filled daily with the sodium citratechloride solution, recommended ${ }^{5}$ in the paper referred to.

The first noticeable result was an increase in the amount of discharge. After a week the citrate solution was discontinued and mercury biniodide solution $(1$ in 2,000$)$ substituted, when the discharge diminished; in a few days the citrate solution was resumed and this alteration continued for two months. It was interesting to note how the amount of discharge could be increased or diminished by the alternate use of these solutions. At the end of six weeks from beginning this treatment the cavity held only about ten minims. In another two weeks it only admitted a fine probe and was quite dry. The boy now weighs almost five stones and is apparently in perfect health. Of course this result may be open to the criticism that the cavity, already reduced to a capacity of about two drachms, would have become obliterated by time and drainage, without the supplementary treatment just described. The capacity of the cavity, however, had been stationary for three months when this treatment was resorted to, And this circumstance seems to warrant its inclusion in the type discussed by Mr. Godlee as follows ${ }^{6}$ :

If we suppose a case in which the various walls of this cavity have been drawn in to the utmost possible extent, there is
nothing further to trust to, if things be left alone, than the nothing further to trust to, if things be left alone, than the
filling in of the cavity with granulations. Now, when this has gone on to a certain extent, a degree of tension is established which effectually prevents a continuation of the process. A state is then reached in which the pleura becomes lined with parfectly smooth surface-secreting pus, indeed, but showing no signs of developing fresh granulations.

If, then, the cavity in the case at present under consideration had, as seems likely, reached the point indicated by Mr. Godlee, how did it become obliterated?

One might suppose (1) that the negative pressure, secured by the use of the cupping glass, would contribute something in this direction, (a) by favouring local pulmonary re-expansion, (b) by the induced hyperaemia stimulating granulation; (2) that the hyper-transudation, which ensued upon the instillation of the sodium citrate-chloride solution, would, in conformity with recent pathology, be credited with an inhibition of bacterial activity and a diminution of the tryptic potency of the pus-thus rendering fresh granulations less liable to erosion.

But, however much, or however little, truth there may be in such speculations, the impression left on one's mind is very strong that the final satisfactory result had been greatly accelerated.

I take this opportunity of expressing my indebtedness to Dr. Mitchell, Anaesthetist to St. Mary's Hospital, who gave chloroform for me on both occasions, for several valuable suggestions.

1 Lancet, 1886, p. 144. 2 Ibid. ${ }^{3}$ British Medical Jotrnal, Novemher 9th, 1907, p. 1295. 4 The Practitioner, May, 1908, p. 592 . 5 Ibid. p. 634 . 6 Loc. cit.

AT a meeting of the Governors of the West Bromwich District Hospital on August 15th it was stated that it had been decided to hold a conference with reference to abuse of the out-patient department. The working class in the neighbourhood is supporting the Hospital Saturday movement well, but it would appear that among some con. tributors there is an idea that contributions to this fund establish a right to treatment and medicinc irrespective of financial position.

\section{SEVENTY-SIXTH ANNUAL MEETING}

OF THE

\section{Partitish Attèital Assuriation.}

Held at Sheffield on July 24th, 25th, 27th, 28th, 29t7a $30 t h$, and 31st.

PROCEEDINGS OF SECTIONS.

\section{SECTION OF PUBLIC HEALTH AND} FORENSIC MEDICINE.

\author{
President, Professor Henry Harvey Littlejohn, \\ M.B., F.R.S.E.
}

PRESIDENTIAL ADDRESS.

Allow me in the first instance, in the name of the Executive Committee, to welcome you, and to express the hope that during the next three days the work of the Section will prove of no less value to ourselves than to the general cause of public health. I desire also to express my appreciation of the honour which has been conferred upon me by being asked to preside over this Section. It has afforded me special gratification to occupy this honourable position in a city which is associated with many happy years of my life during which I held the office which is now so ably filled by my friend, Dr. Scurfield.

I believe there are few, if any, other cities in which the work of a medical officer of health presents greater variety, or in which the problems to be dealt with are of a more fascinating character.

Amongst the factors which lend special interest to the public health administration of Sheffield may be men tioned, first of all, the people themselves, their strong individuality characterized by shrewdness and sound common sense, an outspoken frankness and no inconsiderable amount of humour, while, although strongly conservative in all questions affecting sanitation, they yet are quite open to argument, and, when once convinced, are loyal in their conversion, and bear no ill will for any harch knocks which may have been received during the course of the argument.

I venture to think that no inconsiderable part of what a health officer is able to accomplish, and of the zest. with which he takes up his daily duties, depends more upon his own personal qualities and upon those of the community he has to deal with, than upon his own scientific attainments and the force of legislative enactments.

Then we have a circumstance which is of great im. portance, and intimately associated with the public health administration of Sheffield, in the rapid and enormous. growth which has transformed in less than a century a town of scarcely 50,000 inhabitants to the position of the seventh largest city of the United Kingdom, with a population of 450,000 .

These figures do not, however, represent the real sig. nificance of the growth of Sheffield from a sanitary point of view, because it was only in the Sixties-the period in which England's trade prosperity began to take such an enormous bound; the period in which such a revolution. began to be made in naval construction and armamentthat we find the population increasing with a rapidity beyond all ordinary rule or calculation.

Such a rapid increase of a community such as we can still only observe in the western cities of America leaves an imprint on the town of a more or less permanent character, and is attended by evils which are difficult to eradicate.

In the case of Sheffield it had a far-reaching influence, both from the point of view of aesthetics and sanitation It accounts for what is apt to strike a visitor on first arrival-the narrowness of many of the streets and their unimposing character, together with, in many quarters ${ }_{r}$ the poor nature of the houses and their surroundings.

It must be remembered, however, that the city could not kecp pace with the vast flow of men and women to 